\title{
Preparation and characterization of a novel benzimidazolium brønsted acidic ionic liquid and its application in esterifications
}

\author{
SHUAN-HU CHEN*, QIONG ZHAO and XUE-WANG XU \\ Department of chemistry, Northwest University, Xi'an 710069, China \\ e-mail: csh318361@163.com
}

MS received 22 October 2007; revised 21 April 2008

\begin{abstract}
A novel brønsted acidic ionic liquid 1-butylbenzimidazolium tetrafluoroborate ([Hbbim] $\mathrm{BF}_{4}$ ) based on the benizimidazolium cation was synthesized and characterized. This new ionic liquid was successfully used as a suitable catalyst for the esterifications of carboxylic acids with aliphatic alcohols.
\end{abstract}

Keywords. Ionic liquids; benzimidazole; esterifications.

\section{Introduction}

Ionic liquids (ILs), also known as molten salts with melting point under 100 or $150^{\circ} \mathrm{C}^{1}$, have attracted an increasing attention in the context of green synthesis in recent years. Although ionic liquids were initially introduced as an alternative green media because they are room temperature molten salts that are nonvolatile, thermally stable, recyclable, and easy to handle, ${ }^{2-7}$ they have marched far beyond showing their significant catalytic activities for many reactions. ${ }^{8-11}$ Since the first successful use of ionic liquid, dialkylimidazolium chloroaluminate, as a catalyst in Friedel-Crafts acylations was reported in $1986,{ }^{12}$ a number of ionic liquids with unique properties have been developed and applied to catalyse many types of reactions. ${ }^{13}$ However, just as conventional organic solvents, not all ionic liquids are appropriate for a particular reaction, and a single ionic liquid will not always be the best for every reaction. ${ }^{14}$ It continues to be worthwhile to synthesize novel ionic liquids for particular chemical processes even though a large number of these new compounds are already known.

Recently, Dai et al reported the synthesis of a novel brønsted acidic ionic liquid based on benzimidazolium cation, 1-ethylbenzimidazolium tetrafluoroborate $\left([\mathrm{Hebim}] \mathrm{BF}_{4}\right)$ and found that it was an efficient medium for the preparation of arylic esters. ${ }^{15}$ In this paper, we describe fully the preparation and characterization of another benzimidazolium

*For correspondence ionic liquid, [Hbbim $] \mathrm{BF}_{4}$ and study its application in the esterifications of several carboxylic acids with aliphatic alcohols (scheme 1).

\section{Experimental}

\subsection{Materials and reagents}

All chemicals (AR grade) were commercially available and used without further purification unless otherwise stated. Infrared spectra on $\mathrm{KBr}$ pellets were recorded on a Bruker EQUINOX-55 FT-IR spectrophotometer in the range $4000-400 \mathrm{~cm}^{-1}$. Elemental analyses were determined with a Perkin-Elmer model 240C instrument. ${ }^{1} \mathrm{HNMR}$ spectra in propanone- $d_{6}$ solution using a Varian INOVA-400 spectrometer; proton chemical shifts were recorded relative to an internal TMS standard. The differential scanning calorimetry (DSC) experiment and the thermal stability of each ionic liquid was performed using Q1000DSC+LNCS+FACS Q600SDT at a heating rate $5^{\circ} \mathrm{Cmin}^{-1}$ with nitrogen as the purge gas. Esterification reaction progress was monitored by GC-MS (AligentGC: $6890 \mathrm{~N}, \mathrm{MS}: 5793 \mathrm{~N}$ ).

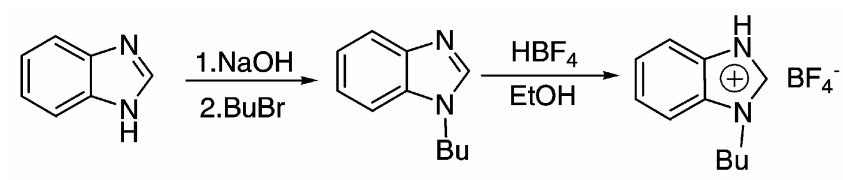

Scheme 1. The synthetic process of ionic liquid. 


\subsection{Synthesis of ionic liquid [Hbbim] $\mathrm{BF}_{4}$}

2.2a 1-butyl benzimidazole ([bbim]): The synthesis process was carried out according to the previous literature. ${ }^{16}$ A mixture of $11.8 \mathrm{~g}(0.1 \mathrm{~mol})$ of benzimidazole, $30 \mathrm{ml}$ of $50 \%$ sodium hydroxide and $8.7 \mathrm{ml}(0.11 \mathrm{~mol})$ of 1-bromobutane were placed in a three-necked flask, which was provided with a mechanical stirrer, reflux condenser, and the thermometer. The reaction mixture was stirred for $3 \mathrm{~min}$. When the mixture solidified, the temperature of the water bath was raised to $30-40^{\circ} \mathrm{C}$ and the content became liquid. After $2 \mathrm{~min}$ an exothermic effect was observed, and the temperature of the reaction mixture was maintained at $30-40^{\circ} \mathrm{C}$ for $10 \mathrm{~min}$. The organic layer was extracted with $\mathrm{CHCl}_{3}(3 \times 30 \mathrm{ml})$, washed with water and dried with anhydrous sodium sulfate. The solvent was evaporated in vacuum, and the oil obtained was purified by distillation.

$2.2 \mathrm{~b}$ l-butylbenzimidazolium tetrafluoroborate ([Hbbim] $\left.\left.\mathrm{BF}_{4}\right)\right]$ : Tetrafluoroboric acid $(40 \%$ solution in water) was added drop-wise to a pre-cooled $\left(0-5^{\circ} \mathrm{C}\right)$ ethanol solution of equivalent bbim in a threenecked flask with a mechanical stirrer. The mixture was maintained at that temperature and stirred for an additional period of $3 \mathrm{~h}$. Ethanol and water was removed under vacuum in a rotary evaporator. The viscous residue was dehydrated at $80^{\circ} \mathrm{C}$ in a vacuum oven for $2 \mathrm{~h}$. The dehydrated residue solidified on cooling to a colourless crystalline solid. Yield: $13 \cdot 1 \mathrm{~g}$ (100\%), m.p. $82-84^{\circ} \mathrm{C}$. IR, $v(\mathrm{KBr}): 3338,3148$, $3028,2962,2872,1616,1551,1498,1450,1382$, $1319,1057,754 \mathrm{~cm}^{-1} .{ }^{1} \mathrm{HNMR}\left(400 \mathrm{~Hz}, \mathrm{CD}_{3} \mathrm{COCD}_{3}\right.$ $\left.d_{6}\right), \delta: 9.60(s, 1 \mathrm{H}, \mathrm{im}-\mathrm{H}), 8 \cdot 11-8 \cdot 13(m, 1 \mathrm{H}, \mathrm{Ar}-\mathrm{H})$, 8.00-8.02 (m, 1H, Ar-H), 7.71-7.76 (m, 2H, Ar-H), $4.73\left(t, J(\mathrm{H}, \mathrm{H})=7.2 \mathrm{~Hz}, 2 \mathrm{H}, \mathrm{N}-\mathrm{CH}_{2}\right), 2 \cdot 07-2 \cdot 13$ $(m, 2 \mathrm{H}), 1.44-1.54(m, 2 \mathrm{H}), 0.98(t, J(\mathrm{H}, \mathrm{H})=$ $7 \cdot 4 \mathrm{~Hz}, 3 \mathrm{H})$. Elemental analysis calcd. (\%) for $\mathrm{C}_{11} \mathrm{H}_{15} \mathrm{~N}_{2} \mathrm{BF}_{4}(262.05) \mathrm{C}, 50.42 ; \mathrm{H}, 5.77 ; \mathrm{N}, 10.69$. Found C, 50.47; H, 5.84; N, 10.75 .

\subsection{Esterifications in novel ionic liquid}

Ethanol $0.46 \mathrm{~g}(0.01 \mathrm{~mol})$, equivalent acetic acid $0.06 \mathrm{~g}(0.01 \mathrm{~mol})$ and ionic liquids $[\mathrm{Hbbim}] \mathrm{BF}_{4} 1.31 \mathrm{~g}$ $(0.005 \mathrm{~mol})$ were added in a flask with a reflux condenser and oil-bath. The reaction mixture was stirred for $2 \mathrm{~h}$ with the oil bath at $80^{\circ} \mathrm{C}$. Reaction progress was monitored by GC-MS. After the reaction, the ester was simply decanted from the ionic liquid, and the ionic liquid [Hbbim] $\mathrm{BF}_{4}$ was reused after removal of water under vacuum $\left(0.01\right.$ Torr) at $80^{\circ} \mathrm{C}$ for $2 \mathrm{~h}$.

\section{Results and discussion}

\subsection{Synthesis of ionic liquid}

The $[$ Hbbim $] \mathrm{BF}_{4}$ ionic liquid was prepared by simple acid-base neutralization from the corresponding 1-butyllbenzimidazole with tetrafluoroboric acid. Ethanol was used as the solvent because of the high solubility involved. The reaction was carried out in an ice bath and required little time or labour. The molecular structure of the ionic liquid was characterized via FT-IR, ${ }^{1}$ HNMR and elemental analysis. All the data of characterization are in accordance with the expected compositions and structures.

\subsection{Solubility}

The solubility property of $[\mathrm{Hbbim}] \mathrm{BF}_{4}$ in some common solvents was studied. It was completely soluble in water, ethanol, methanol, acetonitrile and acetone and immiscible with benzene, toluene, cyclohexane, ethyl acetate and diethyl ether.

\subsection{Thermal stability and DSC measurement}

The thermogravimetric analysis experiment was conducted to determine the thermal stabilities of the novel ionic liquid. Although the study ${ }^{17}$ indicated that the new ionic liquid began to decompose at slightly lower temperature than that of imidazole series, it also displayed high thermal stability. The sample was stable to temperature of $210^{\circ} \mathrm{C}$ and showed a weight loss of $90 \%$ between 220 and $270^{\circ} \mathrm{C}$. When the temperature was $290^{\circ} \mathrm{C}$, the amount of residue was only $0.5 \%$. Thus, it has potential usage as alternative to conventional organic solvents due to its special solubility and excellent thermal stability.

\subsection{Esterifications in the novel ionic liquid [Hbbim] $\mathrm{BF}_{4}$}

The esterifications of several carboxylic acids with common aliphatic alcohols were carried out using the $[\mathrm{Hbbim}] \mathrm{BF}_{4}$ as a catalyst. Higher yields were obtained because of the good solubility of the acids and alcohols in [Hbbim] $\mathrm{BF}_{4}$ while the esters are almost immiscible with ionic liquid. The benzimidazolium novel brønsted acidic ionic liquid which was screened as a catalyst for esterifications of carboxylic acids and aliphatic alcohols could be easily reused after 
Table 1. Results of esterification for different acids and alcohols in [Hbbim]BF 4 .

\begin{tabular}{lllccc}
\hline Entry & \multicolumn{1}{c}{ Acid } & \multicolumn{1}{c}{ Alcohol } & Time $(\mathrm{h})$ & T $\left({ }^{\circ} \mathrm{C}\right)$ & Yield (\%) \\
\hline 1 & Acetic acid & 1-butanol & $2 \cdot 0$ & 120 & 96 \\
2 & Acetic acid & iso-butyl alcohol & $2 \cdot 0$ & 120 & 89 \\
3 & Acetic acid & sec-butyl alcohol & $2 \cdot 0$ & 120 & 71 \\
4 & Acetic acid & tert-butyl alcohol & $2 \cdot 0$ & 120 & 58 \\
5 & Acetic acid & Ethanol & $2 \cdot 0$ & 80 & 96 \\
6 & Oxalic acid & 1-butanol & $8 \cdot 0$ & 120 & 93 \\
7 & Benzoic acid & Ethanol & $8 \cdot 0$ & 80 & 86 \\
\hline
\end{tabular}

${ }^{a}$ In the reaction of oxalic acid, no monoesterification products were detected when the molar ratio of acid to alcohols was $1: 2$

Table 2. Reuse of $[\mathrm{Hbbim}] \mathrm{BF}_{4}$ in the synthesis of acetic acetate.

\begin{tabular}{lccc}
\hline Run & Time $(\mathrm{h})$ & $\mathrm{T}\left({ }^{\circ} \mathrm{C}\right)$ & Yield (\%) \\
\hline 1 & $2 \cdot 0$ & 80 & 95 \\
2 & $2 \cdot 0$ & 80 & 95 \\
3 & $2 \cdot 0$ & 80 & 94 \\
4 & $2 \cdot 0$ & 80 & 95 \\
5 & $2 \cdot 0$ & 80 & 95 \\
6 & $2 \cdot 0$ & 80 & 94 \\
\hline
\end{tabular}

removal of water under vacuum. Its catalytic activity was still very high after 6 times reuse.

The esterification results of several different acids with alcohols were outlined in table 1 . It can be found that the $[\mathrm{Hbbim}] \mathrm{BF}_{4}$ is of high activity for esterification, and esterification of aromatic acids gave lower yields compared with those of aliphatic acids. No by-product was detected.

The results in table 1 also suggested that the esterifications of acids with primary alcohols was satisfactory, followed by secondary alcohols. The lower yield of tertiary alcohols (Entry 4, table 1) was due to the increase in the steric interaction.

The $[$ Hbbim $] \mathrm{BF}_{4}$ is miscible with water and immiscible with ethers, so the esterifications proceeded smoothly for completion even without simultaneous removal of the produced water, even though esterification is a reversible reaction. The ionic liquid could be easily recycled. After reaction, the ionic liquid was simply separated and regenerated by removal of the water in vacuum. It was reused repeatedly over 6 times in the esterification of acetic acid with ethanol, and its catalytic activity was unchanged (table 2).

\section{Conclusion}

The esterifications of aliphatic acids in a novel brønsted ionic liquid were investigated. The results indicated that the ionic liquid $[\mathrm{Hbbim}] \mathrm{BF}_{4}$ showed good catalytic activity to the esterifications and high yields were obtained under mild reaction conditions. After the reaction, the esters could be easily separated; the ionic liquids could be recycled at least 6 times without a significant decrease in catalytic performance.

\section{Acknowledgement}

This project was supported by the Natural Science Foundation of Shaanxi Province (No. 03B19), China.

\section{References}

1. Huddleston J G, Visser A E and Reichert W M 2001 Green Chem. 3156

2. Welton T 1999 Chem. Rev. 992071

3. Wassercheid P and Keim W 2000 Angew. Chem., Int. Ed. 393772

4. Davis J H and Fox P A 2003 Chem. Commun. 111209

5. Shedon R 2001 Chem. Commun. 232399

6. Leitner W 2003 Nature 423930

7. Brown R A, Pollet P, Mckert C A, Litta C L and Jessop P G $2001 \mathrm{~J}$. Am. Chem. Soc. 1231254

8. Zhu A L, Jiang T, Wang D, Han B X, Liu L, Huang J, Zhang J C and Sun D H 2005 Green. Chem. 7514

9. Ranu B C and Jana R 2005 J. Org. Chem. 708621

10. Akaiyama T, Suzuki A and Fuchibe K 2005 Synlett. 6 1024

11. Sun W, Xia C G and Wang H W 2003 Tetrahedron Lett. 442409

12. Boon J A, Levinsky J I and Wilkes J S 1986 J. Org. Chem. 51480

13. Tamar L G and Calum J D 2008 Chem. Rev. 108206

14. Boovanahalli S K, Kim D W and Chi D Y $2004 J$. Org. Chem. 693340

15. Wang Y Y, Li W, Xu C D and Dai L Y 2007 Chin. J. Chem. 2568

16. Ngo H L, LeCompte $\mathrm{K}$ and Hargens 2000 Thermochimi. Acta 97357

17. Ilarski B 1983 Liebigs Ann. Chem. 61078 